\title{
A espacialidade da tela vertical nas narrativas digitais contemporâneas e as reconfigurações do aspect ratio no audiovisual
}

\author{
The spatiality of the vertical screen in contemporary digital narratives and the \\ reconfigurations of the aspect ratio in the audiovisual
}

La espacialidad de la pantalla vertical en las narrativas digitales contemporáneas y las reconfiguraciones de lo aspect ratio en el audiovisual

\section{José Bidarra - Universidade Aberta | Lisboa | Portugal | jose.bidarra@uab.pt | (D) https://orcid.org/0000-0002-2082-5996.}

Luis Fernando Severo - Universidade Tuiuti do Paraná | Curitiba | Paraná | Brasil | fernandosevero7@gmail.com I (D) https://orcid.org/0000-0002-0849-109X.

Resumo: Ao longo de sua história o cinema adotou diferentes formatos de tela, o chamado aspect ratio, cuja definição sempre esteve a cargo da indústria ou de alguns realizadores de vocação autoral. Utilizando um menor número de variações, a televisão sempre trabalhou com formatos rigorosamente definidos. Entretanto na atualidade 0 enquadramento da dimensão espacial em dispositivos móveis quando usados para filmagens tende a seguir outros modelos, com predominância da tela vertical, que corresponde à principal modalidade de uso do smartphone ou tablet na captura de imagens. A emergência de narrativas digitais, através de selfies e outras formas de intervenção individual, representa uma viragem ideológica em que "o autor" somos todos nós. Trata-se de uma mudança de paradigma que importa debater e analisar à luz das novas mídias e das narrativas que a suportam, já que os modos de representação da experiência visual não cabem mais nas janelas de confinamento que a indústria audiovisual originalmente destinou a eles.

Palavras-chave: Aspect ratio. Tela vertical. Narrativas digitais.

Abstract: Throughout its history, cinema has adopted different screen formats, the so-called aspect ratio, whose definition has always been in charge of the industry or of some authors with an authorial vocation. Using fewer variations, television has always worked with strictly defined formats. However, nowadays the framing of the spatial dimension in new media tends to follow other models, with a predominance of the vertical screen, that corresponds to the main mode of use of the smartphone or tablet in capturing images. The emergence of digital narratives, through selfies and other forms of individual intervention, represents an ideological shift in which "the author" is all of us. It is a paradigm shift that needs to be debated and analyzed in the light of the new media and the narratives it supports, since the modes of representation of the visual experience no longer fit into the confinement windows that the audiovisual industry originally 
intended for them.

Keywords: Aspect ratio. Vertical screen. Digital narratives.

Resumen: A lo largo de su historia, el cine ha ido adoptando diferentes formatos de pantalla, el llamado aspect ratio, cuya definición siempre ha estado a cargo de la industria o de algunos autores con vocación autoral. Utilizando un número menor de variaciones, la televisión siempre ha funcionado con formatos estrictamente definidos. Sin embargo, hoy en día el encuadre de la dimensión espacial en dispositivos móviles suele seguir otros modelos, con predominio de la pantalla vertical, que corresponde al modo principal de uso del teléfono móvil o tableta en la captura de imágenes. El surgimiento de las narrativas digitales, a través de selfies y otras formas de intervención individual, representa un punto de inflexión ideológico en el que "el autor" somos todos. Se trata de un cambio de paradigma que necesita ser debatido y analizado a la luz de los nuevos medios y las narrativas que lo sustentan, ya que los modos de representación de la experiencia visual ya no encajan en las ventanas de confinamiento de la industria audiovisual.

Palabras clave: Aspect ratio. Pantalla vertical. Narrativas digitales. 


\section{Introdução}

O cinema nasceu sob o signo da exploração comercial. Na célebre sessão de 1895 em Paris, onde os Irmãos Lumière apresentaram pela primeira vez sua invenção, é cobrado ingresso de um público que se encontra na condição passiva de receptor de imagens manipuladas por um realizador, que naquele momento não é visível. Nesse momento fica instaurada uma relação que vai perdurar no cinema por muitas décadas seguintes, entre os donos dos meios de produção e seu público-alvo, onde todos os processos técnicos e os códigos artísticos que envolvem uma realização cinematográfica não sofrem interferência direta de quem os assiste. Em relação aos filmes de vocação comercial que circulam pelos circuitos tradicionais o público pode no máximo externar sua aprovação ou rejeição a um determinado gênero ou estilo ou a certos atores e atrizes comparecendo ou não às salas de cinema. O processo de produção the é alheio e sua aproximação ao espetáculo cinematográfico ficcional acontece primordialmente por meio dos valores estabelecidos pelo star system. Ficam assim lançadas as bases do cinema dentro do fenômeno que a Escola de Frankfurt vai chamar de indústria cultural.

Nas primeiras décadas do cinema, o documentário de longametragem não é um gênero comercialmente viável e a maior parte das salas de cinema estão equipadas para exibir filmes exclusivamente na bitola $35 \mathrm{~mm}$, captados por câmeras de alto valor que necessitam especialização técnica no manuseio. A definição da bitola de um filme traz implícita determinados limites de acesso e posturas que diferenciam os chamados profissionais dos amadores. Os primeiros são os técnicos e artistas oficialmente capacitados para realizar um filme dentro de certos padrões convencionados que estabelecem parâmetros de qualidade. Nessa perspectiva é definido como amador quem utiliza a técnica cinematográfica para a produção de filmes sem estar submetido a nenhum rigor avaliativo, operando numa zona fora dos interesses comerciais que movimentam a indústria cinematográfica. A esses amadores resta o acesso a bitolas como $16 \mathrm{~mm}$ e Super 8 , utilizadas na maioria dos casos para a realização de home movies ou registros de viagens e passeios. Das duas somente a bitola $16 \mathrm{~mm}$ tem uso profissional, majoritariamente na realização de documentários e ficção 
independente. O surgimento de câmeras de vídeo acessíveis e a posterior ascensão do cinema digital, que torna os equipamentos mais baratos e fáceis de operar, não altera substancialmente essa dicotomia profissional/amador. A indústria cultural continua a não encontrar um lugar para a produção audiovisual que não seja resultado de suas demandas ou que não gere lucros no interior dos mecanismos de distribuição e exibição. Mas a chegada dos celulares e tablets com capacidade de efetuar registros audiovisuais, a partir da primeira década do século 21, vai apresentar as primeiras fissuras nesse campo blindado, onde as empresas voltadas ao entretenimento e os conglomerados de mídia há décadas impõem seus valores sem serem questionados ou contestados.

\section{0 aspect ratio ou formato de tela}

Aspect ratio é o termo da língua inglesa que designa a proporção entre a largura e a altura de uma imagem, aquilo que em um filme definimos na língua portuguesa como formato ou proporção de tela. É um valor tecnicamente expresso por números separados por dois pontos, como por exemplo $4: 3$ ou 1.33:1, indicativo de que a imagem tem $X$ unidades de largura $Y$ unidades de altura. Em seus inventos que deram origem ao cinema como arte e técnica, os pioneiros Thomas Alva Edison e Irmãos Lumière definiram como formato padrão para o enquadramento da câmera o retângulo na proporção 4:3. Segundo Lev Manovich (2001), em The language of new media,

o cinema herda esse enquadramento da pintura ocidental, desde a Renascença a tela pictórica atua como um recorte que pressupõe a existência de um espaço maior fora do quadro, e dividindo-o entre o onscreen space, aquele que está dentro da tela, e o que está fora dela. (MANOVICH, 2001 , p. 80 , tradução nossa).

Entre as convenções recorrentes da pintura figurativa nos séculos que precedem a existência do cinema está o uso da tela retangular e horizontalizada para a representação de paisagens, espaços urbanos e narrativas, enquanto a tela vertical é reservada na maior parte dos casos 


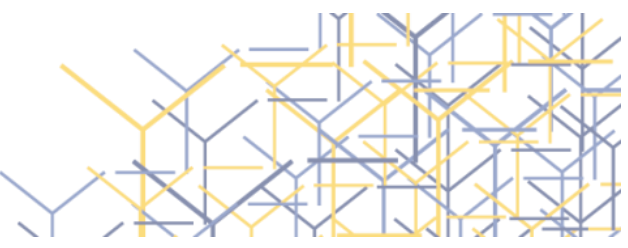

para a arte do retrato. Nessa perspectiva o formato de tela preferencial para o artista escolher o enquadramento de sua representação pictórica estabelece uma espécie de janela para o mundo e "nos apresenta a realidade visível - interiores, paisagens, seres humanos - dispostos no interior de uma moldura horizontal. A estética dessas disposições varia da extrema rarefação à extrema densidade" (MANOVICH, 2001, p. 327, tradução nossa). Segundo Jacques Aumont em A estética do filme esse recorte da imagem define nossa apreensão da representação fílmica, cujos traços fundamentais são decorrentes de sua bidimensionalidade e caráter espacialmente limitado (AUMONT, 2008, p. 19). Ao emular o formato de tela de uma pintura, o aspect ratio define para o espectador um quadro cujo alcance estabelece sua visão de mundo a partir da contemplação do filme na tela.

Esse quadro, cuja necessidade é evidente (não é possível conceber uma película infinitamente grande), vê suas dimensões e suas proporções serem impostas por dois dados técnicos: a largura da película-suporte e as dimensões da janela da câmera, o conjunto desses dois dados define o que chamamos de formato do filme. (AUMONT, 2008, p. 20).

O estabelecimento dessa janela de contemplação descortina para o espectador um universo visual que expressa a individualidade do olhar do realizador cinematográfico, indo além de um simples "corte praticado no mundo dos aspectos visíveis" (DIDI-HUBERMAN, 2012). Durante décadas somente o olhar referendado pela chancela do trabalho profissional estava autorizado a propor esse recorte de visualização nas mídias de exibição do cinema e da televisão, fator que só vai se alterar no início do século 21 com a popularização dos dispositivos móveis que possuem câmeras acopladas.

\section{Uma janela que se expande}

O formato $1.33: 1$, adotado pelos pioneiros do cinema, permaneceu inalterado até o desenvolvimento do cinema sonoro, que acontece na segunda metade dos anos 1920. Como uma das bordas da película passa a ser ocupada pela banda sonora, foi necessária uma alteração quase imperceptível nessa 


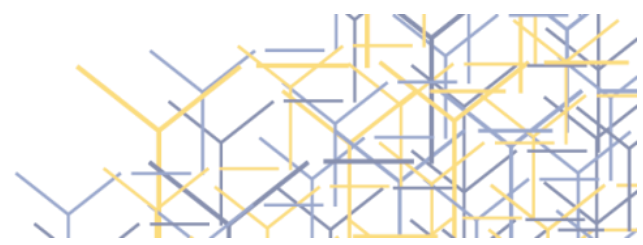

proporção, agora denominada 1.37:1 e oficialmente aprovada pela Academy of Motion Picture Arts and Sciences em 1932. O formato resultante passa a ser chamado de academy ratio (formato acadêmico) e torna-se o padrão oficial de filmagem e projeção do cinema até o início dos anos 1950. Essa é a época em que a expansão no número de emissoras e o aumento da comercialização dos aparelhos de televisão provoca uma queda drástica nas vendas de ingressos para as salas de cinema. Com a produção cinematográfica americana concentrada no modelo studio system ${ }^{1}$, coube aos estúdios propor medidas que estanquem a crescente perda de público para a ameaça que se instala cada vez mais nos lares americanos. Em contraste à tela pequena que copia o academy ratio e ao som monofônico dos aparelhos de TV, o cinema de estúdios investe no som estereofônico e na expansão do formato de tela como forma de reconquistar o fugidio público pagante. Embora o formato acadêmico permaneça em uso na maior parte das produções da época, os grandes estúdios investem em novos formatos widescreen, telas panorâmicas apresentadas ao público com os nomes comerciais CinemaScope, Panavision, VistaVision, Todd-AO e Cinerama. Esse formato expandido obtém sucesso em dissociar o cinema visto nas telas dos filmes exibidos na televisão, trazendo de volta parte do público pagante perdido, mas a exigência de câmeras e projetores dotados de lentes anamórficas encarece o processo de produção e exibição e as coisas se encaminham para uma solução alternativa.

Um formato intermediário entre o acadêmico e o widescreen ganha corpo nas décadas de 1960 e 1970, e as proporções 1.66:1 e 1.85:1 tornam-se standards ficando o formato anamórfico e similares como o $70 \mathrm{~mm}$ restritos às superproduções dos estúdios. Para serem exibidos no formato acadêmico pelas emissoras de televisão, os filmes em tela panorâmica sofrem cortes e mutilações em seus enquadramentos e movimentos de câmera, sendo

${ }^{1}$ O studio system, termo associado um período conhecido como a "Idade de Ouro" de Hollywood, é um método de produção e distribuição de filmes dominado por um pequeno número de estúdios dotados de grande poder financeiro e capacidade produtiva. 


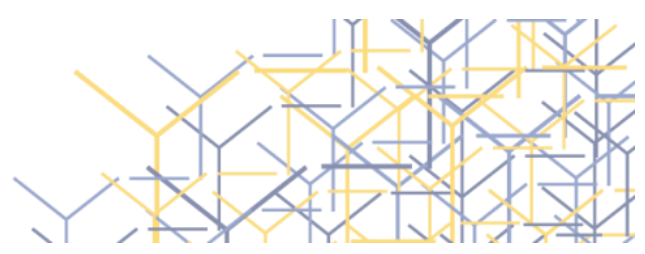

submetidos a um processo chamado pan and scan, rejeitado por diretores, críticos e cinéfilos.

\section{A transição da película para o digital}

Enquanto a tela da TV permanece estandardizada no formato acadêmico até o momento histórico de sua transição para o meio digital, na indústria cinematográfica as transformações dos formatos são definidas de acordo com os interesses econômicos e sem qualquer participação do público. Sistemas alternativos ou independentes de produção são mantidos à margem das redes de distribuição e exibição. Dentro desse processo permanece intocado o panorama relativo ao acesso dos amadores às câmeras e a exclusão de sua produção fílmica de quase todas as instâncias que possibilite um contato com a grande público. Ao contrário dos profissionais do cinema, que possuíam acesso à câmeras que filmavam em diferentes formatos, aos amadores destinavam-se equipamentos com formatos pré-definidos segundo os parâmetros da indústria. Nos anos 1980, a câmera VHS junta-se ao 16mm e ao Super 8 no rol das possibilidades de uso doméstico, e seu formato reproduz o academicismo da tela de TV. Em 1985, Gilles Deleuze afirma, em A imagemtempo, que "A imagem eletrônica, isto é, a imagem de televisão ou vídeo, devia ou transformar o cinema, ou substituí-lo, marcar sua morte". (DELEUZE, 2009, p. 315). Nenhuma dessas possibilidades preconizadas por Deleuze acontece. Experimentações que envolvem o uso de suportes alternativos, como o uso de diversas bitolas de vídeo na produção de imagens cinematográficas fracassaram em sua busca de um hibridismo entre cinema e vídeo, mesmo levadas a cabo por cineastas do calibre de Michelangelo Antonioni (O mistério de Oberwald, 1981) e Francis Ford Coppola (O fundo do coração, 1981).

O final da década de 1990 assinala o surgimento de uma nova era para o cinema, é o momento em que o uso da película e os processos analógicos a ela associados começam a ser substituídos pelo cinema digital, filmado 


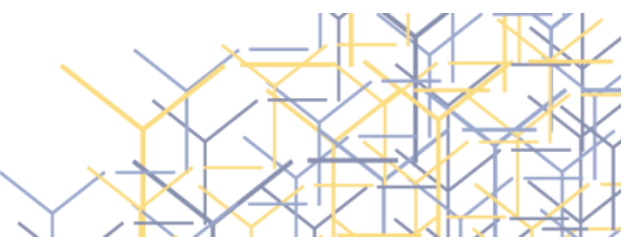

inicialmente por câmeras de vídeo. Não foi uma transição pacífica, a película esteve associada aos primeiros cem anos do cinema e está indissoluvelmente ligada à estética, à linguagem e ao estilo dos filmes produzidos nesse período. Por essa razão a nova tecnologia audiovisual inicialmente foi recebida com reservas e sua metamorfose de vídeo em cinema sofreu resistência.

O cinema digital, armazenando imagens e sons nos bits e
bytes de aparatos computadorizados, desmaterializou a
superfície que, por mais de um século, abrigou fotogramas,
constituindo-se na substância poética em que foram
impressionadas as mais pregnantes sensações, visões e
fantasias do século XX. [...] Essa suposta desaparição (ou
metamorfose) do cinema, como toda crise, representa tanto
um momento de nostalgia pelo término de algo como de
oportunidade e abertura ao novo. (FELINTO, 2006, p. 413).

O sucesso do movimento dinamarquês Dogma 95, com seus filmes realizados com câmeras de vídeo semi-amadoras, ajudou a pavimentar o caminho do cinema digital, graças ao sucesso e premiação no Festival de Cannes e indicação ao Oscar, as duas maiores vitrines do cinema como arte e indústria.

\section{Smartphones, tablets e a instauração de novos conceitos imagéticos}

Um dos grandes fenômenos de mass media no começo do século 21 foi a popularização dos telefones celulares, que mesmo em suas primeiras versões já permitiam um registro imagético de baixa resolução. Sua evolução para o formato smartphone e o surgimento dos tablets possibilitaram a incorporação de câmeras de boa resolução e fácil manuseio, deixando de ser meros dispositivos emissores e receptores de formas verbais de comunicação, o que permitiu que qualquer pessoa produzisse imagens estáticas ou em movimento de forma praticamente ilimitada. Essa evolução tecnológica foi acompanhada pela disseminação das redes sociais e a abertura de portais como o YouTube, que rapidamente tornam-se plataformas democráticas e ilimitadas de exibição. 


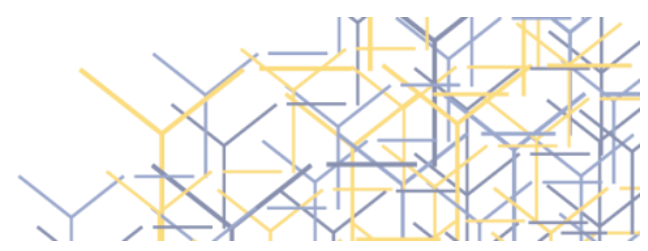

Neste cenário da cultura da convergência, debatido por Henry Jenkins (2014), a propagabilidade torna-se evidente, pois cria-se um ambiente onde a interatividade e a participação individual são as referências mais marcantes. Segundo Jenkins, a propagabilidade relaciona-se aos deslocamentos de conteúdo, ou seja, aos modelos de aderência que circulam por meio da interatividade entre as pessoas envolvidas no processo de comunicação. Contudo, foi possível perceber que a propagabilidade se diferencia do antigo status da comunicação que se atinha a projeção de conteúdo em plataformas únicas para públicos amplos. Ao se inserirem socialmente, as novas mídias traçaram novos caminhos para o desenvolvimento das relações entre indivíduos e os meios, desenhando novos alicerces e promovendo aberturas para reinvenções nos processos de criação das mensagens. Na contemporaneidade, a participação da recepção configura novas artimanhas, pois as contribuições espontâneas das pessoas interferem na construção das novas narrativas.

Esse processo significa na prática um empoderamento dos chamados amadores, que mesmo sem treinamento formal, despojados de noções de linguagem cinematográfica e sem a pretensão de ter seus trabalho exibidos fora de um círculo pessoal de relacionamentos, acabam guindados à condição de produtores de conteúdo e frequentemente tem seu trabalho apropriado pelas mídias tradicionais. Confrontado com a possibilidade de deixar de ser apenas um consumidor passivo da produção audiovisual esse novo homem com uma câmera recria uma situação primordial do processo da criação audiovisual e produz instintivamente aquilo que em seu livro A imagem câmera Fernão Ramos define como "um plano que seja o fundamento, o grau zero da linguagem cinematográfica, em que o aspecto mecânico que envolve a produção da imagem-câmera encontre sua potencialização maior" (RAMOS, 2012, p. 15). Como não se dirige apenas ao receptor com o olhar educado pelas normas estéticas que regem o cinema e a televisão, o operador da câmera do celular não tem amarras nem limites para expressar sua visão de mundo intermediada por uma imagem-câmera impura, que produz sons e 


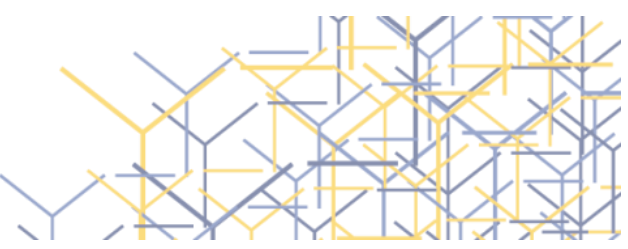

imagens fora dos códigos narrativos tradicionais, mas nem por isso menos potentes.

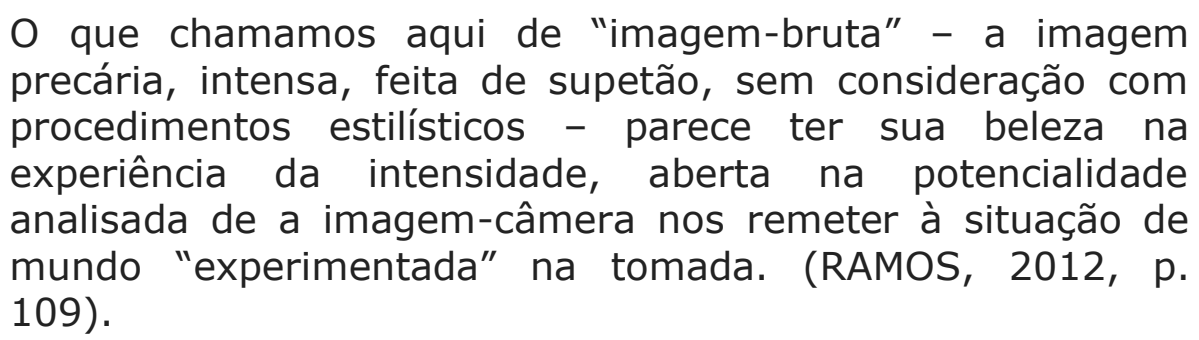

Essa brutalidade a que se refere Ramos é traduzida nas telas amadoras não só pela instabilidade das imagens e pela violação de preceitos intrínsecos aos conceitos de qualidade artística da indústria audiovisual. Entre outras coisas ela introduz um elemento originalmente não validado pelos códigos de produção do cinema e da televisão por causar desconforto estético e se contrapor a seus valores formalmente estabelecidos em termos de registro de imagem: a tela vertical.

\section{A tela vertical como elemento transgressivo}

O formato de tela vertical faz sua primeira aparição no cinema ainda no período silencioso através da prática do mascaramento de parte da imagem visando ressaltar alguns elementos para o espectador, procedimento ao qual David W. Griffith recorre diversas vezes ao longo de Intolerância (Intolerance, Estados Unidos, 1916) e que é abandonado ainda antes da chegada do filme sonoro. Nunca adotado como aspect ratio oficial, o formato vertical pode ser encontrado de forma dissimulada em certas escolhas de mise en scène que grandes cineastas como John Ford e Luchino Visconti introduzem em seus filmes, onde interiores e exteriores aparecem emoldurados através de portas e janelas que delimitam a extensão do enquadramento e verticalizam o olhar. É famosa e muito imitada no cinema a cena final de Rastros de Ódio (The searchers, John Ford, Estados Unidos, 1956), onde o protagonista caminha 


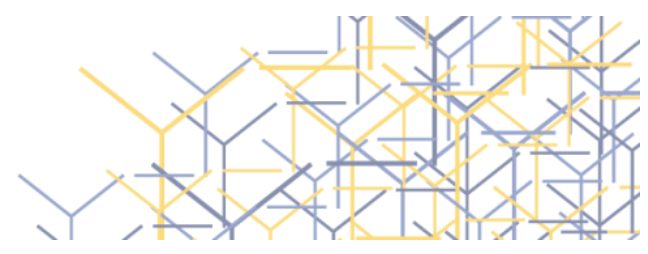

solitário em direção ao Monument Valley enquadrado através da porta de uma casa. Desde 1963 um dos pioneiros da videoarte, Nam June Paik, utiliza a tela vertical como proposta de visionamento de suas experiências que transitam mais pelo campo das artes plásticas do que do cinema, enquanto Bill Viola, nome emblemático da videoarte contemporânea, incorpora a tela vertical a vários de seus processos criativos. Em seu ideário as questões formais traduzidas pela câmera transcendem a uma leitura tecnicista, já que para a minha mente, a tecnologia é, em definitivo, uma força espiritual e uma parte de nosso ser interior. (VIOLA, 1986, p. 74).

A reconfiguração maior trazida pela imagem vertical para os processos comunicacionais contemporâneos não ocorre no interior da produção ficcional do cinema e da televisão mas no âmbito do telejornalismo, que se vê subitamente acuado entre a necessidade de preservar seus padrões qualitativos solidamente preservados por décadas e a necessidade de recorrer a imagens amadoras para não ser atropelado pela velocidade requerida pelo público na busca da informação sobre os acontecimentos cotidianos. No dia 27 de dezembro de 2017, durante o encerramento do Jornal Nacional, telejornal de maior audiência da televisão brasileira, o âncora William Bonner posicionase em frente à bancada, o que é bastante incomum no formato do programa. Em tom professoral, dirige-se diretamente ao telespectador, explicando que a forma correta de se filmar e fotografar com o smartphone é na posição horizontal. Empunhando um aparelho que manipula em sincronia, afirma que "Na hora da pressa, é muito comum filmar assim, com o celular na vertical. Mas para a imagem ser mais bem explorada na televisão [...] o ideal é que a imagem fique na horizontal". Em poucos minutos, o Twitter é tomado por reações desdenhosas e revoltadas provocadas pelo tutorial que tenta enquadrar a liberdade de uso da filmagem em celular, definida de acordo com a vontade de quem usa o aparelho, indicando que a fala de Bonner encontrou pela frente um público bem menos doutrinável do que se supunha dentro da emissora. As filmagens através de celulares e tablets empunhados na posição vertical fornecem, hoje em dia, uma parte significativa dos registros 


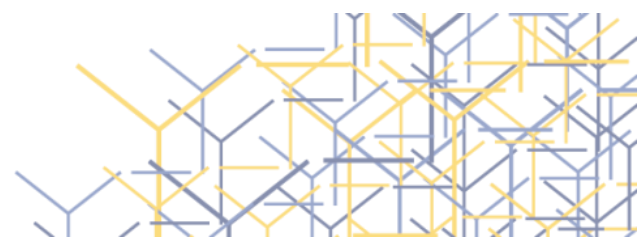

documentais que circulam na mídia, tornando cada vez mais obsoleto o jornalismo diário fundamentado em pautas e equipes de cobertura. Durante décadas, ao recorrer imagens não registradas por seus cinegrafistas as emissoras brasileiras as exibiam com a legenda "imagens de um cinegrafista amador", como se estivessem se desculpando junto ao público pelas imagens diferenciadas de seu padrão de qualidade. A dependência desse tipo de imagem em sua programação diária leva a uma forçosa relação de respeito, que se traduz na obrigação de creditar o nome de quem produziu o conteúdo audiovisual exibido. A imagem captada em tela vertical provoca um notório incômodo no padrão global de qualidade porque com a digitalização da televisão brasileira ${ }^{2}$ o formato acadêmico foi definitivamente abandonado e a tela dos novos televisores se expandiram horizontalmente, abrindo um novo campo visual a ser ocupado pela imagem. Sem saber como lidar direito com os espaços vazios que a imagem vertical provoca em suas telas, as emissoras limitam-se a preenche-los com grafismos que nada acrescentam em termos informacionais ou estéticos, manifestações simbólicas da impotência dos gigantes da comunicação diante dessa derrocada nos planos formais e informacionais que thes impõem os até então desdenhados amadores.

Os novos conceitos de espectatorialidade distanciam os indivíduos que produzem conteúdo audiovisual com seus próprios aparatos tecnológicos do consumidor passivo de conteúdo audiovisual ainda preso a conceitos tecnoestéticos vigentes há décadas. Em A tela global Gilles Lipovestky e Jean Serroy registram o que batizam do fenômeno do "Cine-eu", decorrente do que chamam de "hipermodernidade globalizada", que inclui a possibilidade de realizar obras audiovisuais para si e para seu universo de relações sociais num tempo onde "o individualismo entrou em uma nova fase de sua aventura histórica" (LIPOVETSKY; SERROY, 2009, p. 197).

\footnotetext{
2 A digitalização da televisão brasileira é um processo gradual de transição do sinal analógico para o sinal digital das emissoras de TV. Teve início em 2007, com as primeiras transmissões digitais, em 2018 todas as capitais já haviam concluído o processo. A finalização do desligamento do sinal analógico em todo o Brasil está prevista para 2023.
} 


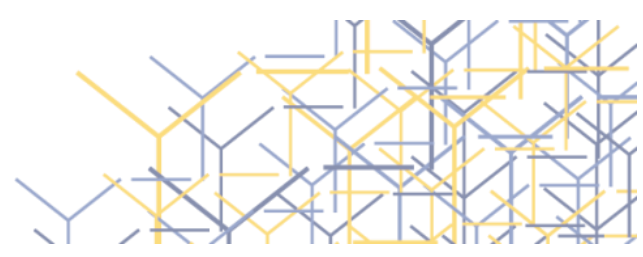

Na verdade, nenhum referencial suscita tantos filmes quanto o próprio indivíduo, o indivíduo em relação consigo mesmo e com os outros. Certamente isso não é novo. Mas a época hipermoderna, movida pelo choque da "segunda revolução individualista", colocou mais do que nunca o indivíduo em cena. (LIPOVETSKY, SERROY, 2009, p. 198).

Num dos ensaios que compõem seu livro Cinema in the digital age Nicholas Rombes argumenta que as variações de registro trazidas pelos equipamentos digitais propiciam diferentes visões da realidade física (ROMBES, 2009, p. 121), rompendo a hegemonia do cinema e da televisão na definição dos códigos visuais.

\section{Considerações finais}

Se para a televisão, o combate à tela vertical é uma causa perdida, o cinema e o universo das séries se aproximam desse formato com cautela. Diretora do documentário Democracia da vertigem, primeiro filme brasileiro do gênero indicado ao Oscar e exibido mundialmente via Netflix, a cineasta Petra Costa publicou no primeiro semestre de 2020 um anúncio convidando pessoas para contribuírem com a realização de seu novo documentário, chamado Dystopia. A proposta é os participantes enviem vídeos narrando as consequências da pandemia em suas vidas e explicando as situações que estão vivendo em decorrência do vírus Covid-19. Um detalhe bem explicitado pelo anúncio chama a atenção: somente serão aceitos vídeos filmados em formato horizontal.

Em outubro de 2020, provocou surpresa na indústria audiovisual, o anúncio do fim das operações do serviço de streaming Quibi, produto de um investimento bilionário de grandes nomes da indústria do entretenimento e lançado para fazer concorrência aos grandes players desse mercado em constante crescimento. Focado na produção de séries com capítulos de curta duração e formatado para ser visto exclusivamente em telefones celulares e tablets, um de seus maiores diferenciais era a possibilidade do usuário assistir 


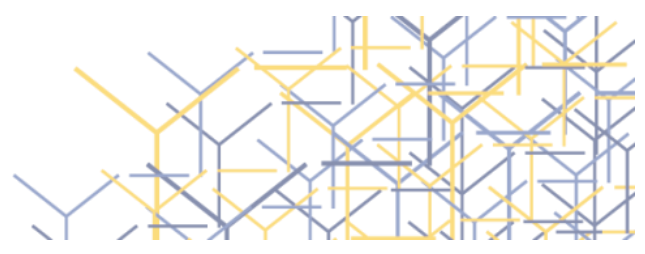

qualquer cena no formato horizontal ou vertical, com a transição entre um e outra feito pela simples rotação do aparelho.

Neste novo contexto, encontramos a capacidade de ver em qualquer momento os conteúdos de vídeo online em diversos formatos, mas também a existência de criação voltada para conteúdos mais curtos, com pouca complexidade e pouco profissionalismo. O consumo em dispositivos móveis, por exemplo, altera a experiência audiovisual, pois com as pequenas telas, a percepção de detalhes é inexistente. As imagens são apresentadas com pouca nitidez e qualidade fotográfica, diminuindo o impacto das cenas com perspectiva, pois altera a profundidade de campo. Percebe-se, também, que a performance de atores ou a profundidade das paisagens são pouco apreendidos pelos consumidores. Como essas limitações não impedem que esses conteúdos esteticamente limitados tenham milhões de acessos, talvez a era digital esteja trazendo profundas transformações na relação do espectador das diversas mídias com a produção audiovisual.

Neste artigo, mostramos como nos contornos das mídias convergentes, a forma de apreensão dos materiais produzidos se moldam a partir de novas formulações. Num cenário futuro, vemos um novo perfil de espectadores de imagens audiovisuais, não mais ligados a velhos e grandes formatos, mas visualizando em pequenas e móveis telas. Pensamos que existirá sempre um local para se contar histórias em formatos "clássicos", por mais que esta ampliação pareça contrapor-se, mas nada altera o fato de que os usuários passaram a ser produtores de materiais multimídia, detentores de informação sempre atualizada e incansáveis comunicadores, em permanente mobilidade.

\section{10
0
0
0}

\section{Referências}

AUMONT, Jacques. A estética do filme. Campinas: Papirus, 2008.

DELEUZE, Gilles. Cinema 2: Imagem-Tempo. São Paulo: Brasiliense, 2009.

DIDI-HUBERMAN, Georges. 0 que vemos, o que nos olha. São Paulo: Editora 34, 2012. 


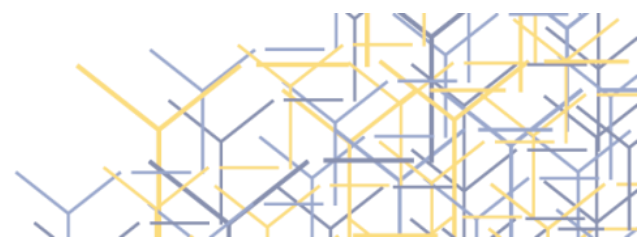

FELINTO, Erick. Cinema e tecnologias digitais. In: MASCARELLO, Fernando (Org.). História do cinema mundial. Campinas: Papirus, 2006.

JENKINS, Henry. Cultura da conexão. São Paulo: Aleph, 2014.

LIPOVETSKY, Gilles; SERROY, Jean. A tela global: mídias culturais e cinema na era hipermoderna. Porto Alegre: Editora Sulina, 2009.

MANOVICH, Lev. The language of new media. Cambridge: The MIT Press, 2001.

RAMOS, Fernão Pessoa. A imagem-câmera. Campinas: Papirus, 2012.

ROMBES, Nicholas. Cinema in the digital age. London: Wallflower, 2009.

VIOLA, Bill. Catalogue de I'exposition Bill Viola, sous la direction scientifique de Jérôme Neutres. Paris: Éditions de la Réunion des musées nationaux, Grand Palais, 1986.

\section{Sobre os autores:}

José Bidarra - Doutor, Docente da UAb, subdiretor do Doutoramento em Média-Arte Digital, Membro do Conselho Coordenador do Departamento de Ciências e Tecnologia - DCT - e Membro das Comissões Científica e Pedagógica do Mestrado em Informação e Sistemas Empresariais - MISE.

Luis Fernando Severo - Doutorando e Mestre em Comunicação e Linguagens - Linha de Pesquisa Estudos de Cinema e Audiovisual pela Universidade Tuiuti do Paraná. Especialista em Comunicação e Cultura pela UTFPR. Realizador de mais de quarenta filmes como diretor, roteirista e montador. Professor no curso de Cinema e Audiovisual da Universidade Estadual do Paraná e na pósgraduação em Cinema da UTP. 